\title{
Use of lateral calcaneal flap for coverage of posterior heel defects
}

\author{
MT Islam1, SN Abdullah², MJ Uddin ${ }^{3}$,TR Rahman ${ }^{4}$
}

\begin{abstract}
Lateral calcaneal flap is frequently used for coverage of lateral calcaneum and posterior heel defects. We conducted a prospective study using lateral calcaneal artery flap to cover posterior heel defects from July 2011 to June 2015 in the Department of Burn and Plastic Surgery, Khulna Medical College to observe the clinical outcome of use of lateral calcaneal artery flap. A total number of ten soft tissue defects in posterior heel with and without exposed Achilles tendon or calcaneus due to different causes were reconstructed with lateral calcaneal artery flap. All ten flaps survived completely with no subsequent breakdown of the skin, even after regular wearing of normal shoes. The flap donor sites were grafted with split-thickness skin grafts in all cases. Partial graft loss was noted in two cases which were eventually healed spontaneously with dressing without the need for a secondary graft. Epidermal necrosis developed in one case which was ultimately healed with conservative treatment. There was no loss of sensation in flap area but sensory disturbance at the lateral part of the dorsum of foot was found in all cases. Our results were satisfactory in terms of coverage adequacy, perioperative morbidity, and functional and aesthetical outcomes. The lateral calcaneal artery skin flap can be used safely to provide sensory skin coverage in posterior heel defects.
\end{abstract}

Key words: Posterior heel defects, lateral calcaneal flap, split-thickness skin grafts, coverage.

\section{Introduction}

The reconstruction of soft tissue defects of the posterior heel (non-weight bearing part of the heel around the tendo Achilles region or those involving weight-bearing area) presents challenging problems for plastic surgeons because of their osseous or tendinous bed, poor area vascularization, continuous movement, and high functional demands. Conservative treatment usually fails, use of split or full-thickness skin grafts often leads to unacceptable results while free flaps transfer is technically demanding and presents significant perioperative morbidity. Posterior heel defects require a well vascularized reconstruction having a good durability and sensation because of its location and repeated friction by footwear. However, with a better understanding of the vascular anatomy of the leg and the availability of microsurgical techniques, flaps can be chosen that are easy to execute quickly and provide durable coverage for the defect. The available flaps include local

1. MT Islam, Assistant Professor, Department of Burn and Plastic Surgery, Khulna Medical College, Khulna

2. SN Abdullah, Junior Consultant (current charge), Shahid Sheikh Abu Naser Specialized Hospital, Khulna

3. MJ Uddin, Assistant Professor, Department of Orthopaedic Surgery, Gazi Medical College, Khulna

4. TR Rahman, Lecturer, Department of Anatomy, Khulna Medical College, Khulna 
flaps, perforator based flaps and lateral calcaneal artery flaps, regional flaps, distally based sural artery flap, distally based posterior calf fasciocutaneous flap and distant flap, cross leg flap and micro vascular flaps. ${ }^{1,2}$

Among these procedures, the lateral calcaneal artery flap which was first described by Grabb and Argenta is frequently used. $^{3}$ Since then, it has been used with different modifications by different surgeons for the coverage of soft-tissue defects of the ankle and foot. ${ }^{4-6}$

In this paper, we describe the clinical outcome of application of pedicled lateral calcaneal artery flap for the coverage of posterior heel with or without exposed Achilles tendon or calcaneus.

\section{Materials and Method}

This prospective observational study was conducted in the Department of Burn and Plastic Surgery, Khulna Medical College Hospital from July 2011 to June 2015. A total number of 10 patients with posterior heel wounds were reconstructed with lateral calcaneal artery flap for coverage of soft tissue defects in posterior heel with or without exposed tendo Achilles or calcaneus due to different causes (example shown in Fig. 1.A). The size of the wound ranged from $6.5 \mathrm{~cm}^{2}$ to $21.5 \mathrm{~cm}^{2}$. The flaps ranged in size from $3.5 \times 2.0 \mathrm{~cm}^{2}$ to $7 \times 3.5 \mathrm{~cm}^{2}$. The follow-up period ranged from 4 to 18 months. No co-morbid illness were considered as exclusion criteria. Patients were included in the study after obtaining an informed consent. All the study variables were collected on pre-designed proforma such as age, sex, procedure performed and complications noted.

The position and course of the calcaneal artery was marked on the skin. With the leg dependent, the course of the lesser saphenous vein was also marked out. The length and width of the desired flaps were planned by using a cloth pattern over the defect and transposing it to lie over the previously demarcated artery (Fig. 1.B). The flap was designed as a short vertical flap or a long flap that curves forward to the base of the fifth metatarsal according to the defect size to be covered. Dissection was begun at the lateral aspect of the calcaneal tendon and was carried down distally to the periosteum of the calcaneus. The plane was then developed leaving the periosteum intact. The anterior incision was made immediately behind the lateral malleolus and carried down through the subcutaneous tissues. Finally the distal horizontal incision was made and the flap was raised in a retrograde fashion to the level of the lateral malleolus. The neurovascular structures lied in the deep surface of the subcutaneous tissues and could be visualized if the dissection was too superficial. Optimally, the vessels were not exposed and therefore not traumatized. The pedicle of the flap lied immediately above the level of the lateral malleolus where the calcaneal artery begins to sink to a deeper level. A minimal amount of dissection facilitated rotation, as deeper dissection may be dangerous. The base of the flap was usually left intact and optimally was at least 4 $\mathrm{cm}$ wide. Rotation to the defect was then performed, and the flap was inset. Donor defect was covered with split-thickness skin graft (Fig. 1.C). Postoperatively, the patient was kept in bed with the leg elevated for 5 to 7 days.

\section{Results}

Among 10 patients, 8 were male and 2 were females. Table 1 shows the age range of patients. Most of the patients (40\%) were in between 20-30 years in this study. The common causes of the defects were due to wound dehiscence from flap necrosis after repair of tendo Achilles (50\%) (Fig. 2). Fig. 3 shows the complexity of wounds. Most of the wounds were exposed tendo Achilles with or without exposed calcaneus. All flaps had good perfusion and survived completely. The complications are shown in Fig. 4. Epidermal necrosis developed in 1 case which was ultimately healed with conservative treatment. Dog ear deformity occurred in $3(30 \%)$ cases where flaps needed much rotation. In 1 case, correction of dog ear deformity was done after 14 months with 

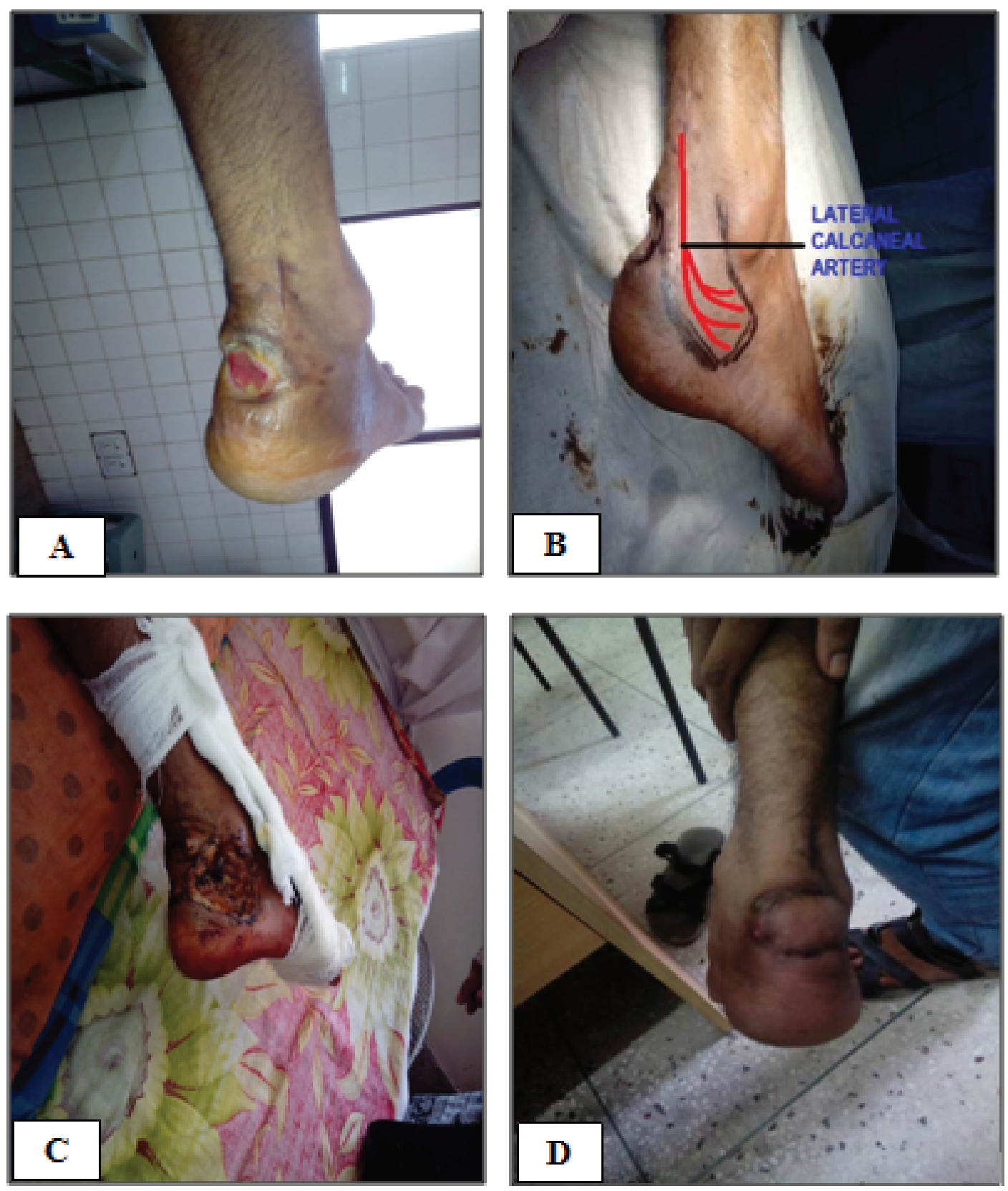

Fig. 1. A) Defect over insertion of tendo Achilles, B) Marking for flap, C) Donor area covered with skin graft and D) Healing, 2 months after operation.

local anesthesia and in other cases it flattened out with time. No venous congestion was noted but flap edema lasted for 3-4 days. The skin grafts on the flap donor site had taken well in all cases except in $2(20 \%)$ cases, partial graft losses were noted which were eventually healed spontaneously with dressing without the need for a secondary graft. In 1 case having partial loss of the split-thickness skin graft that healed spontaneously developed hypertrophic scar.

All patients became ambulatory after wound healing, and ankle motion was not restricted (Fig. 1.D). There was no subsequent breakdown of the flap or the grafted skin with regular wearing of shoes. There was no loss of sensation in flap area but sensory disturbance at the lateral part of the dorsum of foot was found in all cases. All flaps were aesthetically good. 
Table 1. Distribution of age and causes of the defects

\begin{tabular}{lcc}
\hline $\begin{array}{l}\text { Age range } \\
\text { (years) }\end{array}$ & Number & \% \\
\hline $20-30$ & 4 & 40 \\
$31-40$ & 3 & 30 \\
$41-50$ & 1 & 10 \\
$51-60$ & 2 & 20 \\
\hline
\end{tabular}
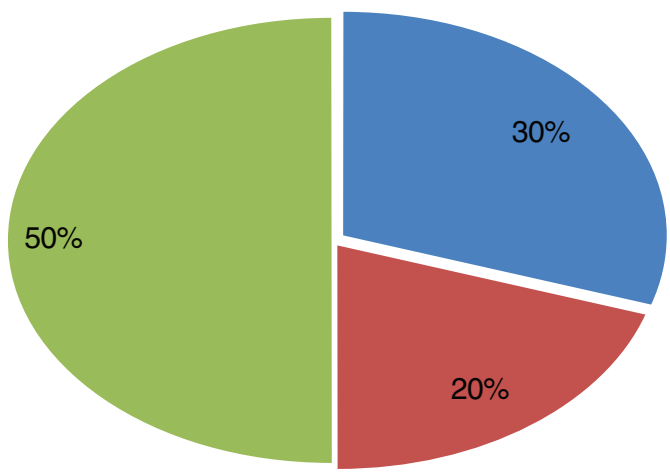

Fig. 2. Distribution of causes of the defects.

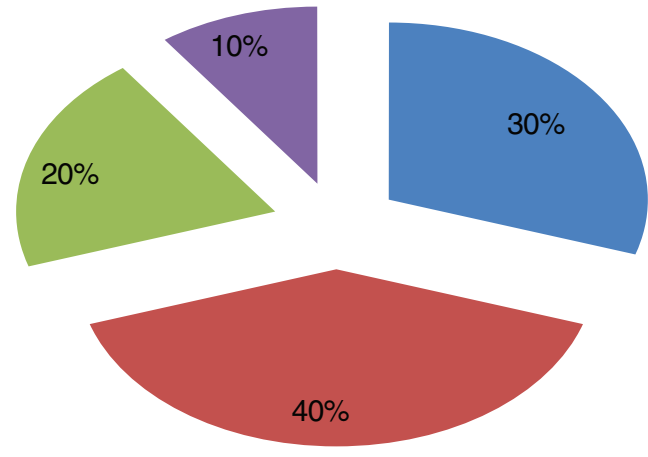

Exposed tendo
Achilles
Exposed calcaneus
Exposed tendo
Achilles with
calcaneus
Underlying fracture
of calcaneus

Fig. 3. Complexity of the injury.

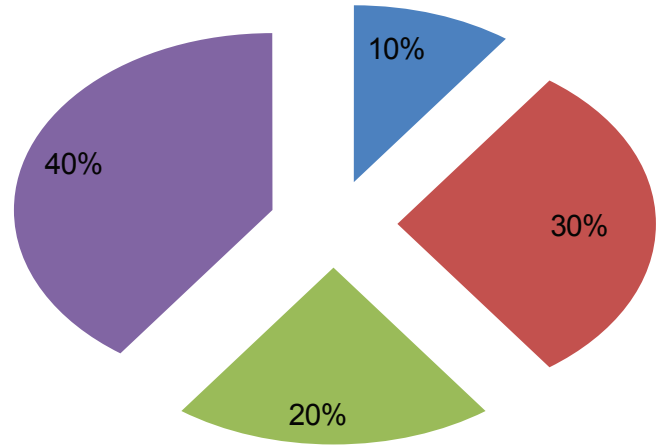

- Epidermal necrosis

- Dog ear deformity

- Partial skin graft loss

- No complication

Fig. 4. Complications. 


\section{Discussion}

Reconstruction of soft-tissue defects of posterior heel poses a continued challenge to plastic surgeons. There are many options for coverage of posterior heel defects like local random pattern flap, lateral calcaneal flap, reverse sural island flap, cross leg flap and free flap. The distally based reverse sural flap is the most well-known flap for reconstruction of the posterior heel. Its broader spectrum of indications, larger vascular territory and great arc of rotation combine to make it a substitute for free tissue transfer for treatment of larger and composite defects. But it is not a good match for the defects of posterior heel as it is more bulky, insensate, usually leaves long linear scars cutting across the ankle and skin grafting is needed in calf region. ${ }^{7}$ Simple method like skin grafting may also be useful in specific situations but it often leads to unacceptable results.

Use of the lateral calcaneal artery skin flap for heel reconstruction has been reported since $1981 .^{3}$ The flap is an axial pattern fasciocutaneous flap that is simple, stable and sensate. It is nourished by the lateral calcaneal artery, which is a terminal branch of the peroneal artery, is drained by the lesser saphenous vein and is innervated by the sural nerve. ${ }^{4}$ It is preferred in small sized isolated posterior heel defects with or without exposed tendo Achilles or calcaneus. ${ }^{2}$ Lower limb vessels are affected in many conditions like smoking, diabetes mellitus. But peroneal vessels are the last to be affected by age, diabetes mellitus or smoking, making it a safe flap in these patients. ${ }^{8}$ Because this fasciocutaneous flap is moved as a transposition flap from the area below the lateral malleolus so a 'dog-ear' or kinking of the pedicle may occur. Disadvantages of the flap are that the donor site requires grafting, which is put on the periosteum giving a depression, and causes a poor cosmetic appearance. Patients also have sensory disturbance at the lateral part of the dorsum of foot. ${ }^{9}$ In their series of seven patients by Hovius et al, two donor sites showed secondary healing and one donor site showed hyperkeratosis resulting from inappropriate planning of the flap. ${ }^{9}$ In our series of 10 patients, two of the donor sites showed minimal grafted skin loss which were healed conservatively with regular dressing.

There are many modifications of lateral calcaneal flap. In 1996, use of the lateral calcaneal artery adipofascial flap was reported for small defects on the ankle. ${ }^{10}$ The advantages of this type of adipofascial flap are that it preserves the sural nerve and does not require skin grafting of the donor site. ${ }^{10}$ Usually, adipofascial flaps are suitable for soft tissue reconstruction on the extremities where a thin flap is desirable, there is no excess skin around the lesion, and a skin graft is not acceptable for aesthetic purposes. The main short coming of this procedure is that additional skin grafts are applied to raw adipofascial flap surfaces. In our study we didn't do adipofascial flap as it did not avoid skin grafting.

Cross leg flap is a two stage procedure. It leaves patients immobile and causes many problems. It is also insensate, bulky and more hospital stay is required. Microsurgical flap reconstruction is a good options for larger defects. ${ }^{6,11}$ But it is bulky, cosmetically less acceptable and needs high expertise.

In comparison to other flap for posterior heel reconstruction, lateral calcaneal artery skin flap is preferable by many surgeons to cover difficult wounds of the posterior heel of the foot. Because it does not require sacrifice of a major artery to the leg or foot, are relatively thin with acceptable morbidity at the donor sites. In addition, the flap dissecting technique is straight forward; vascular pedicle is constant and surgical transfer easy. Use of the lateral calcaneal flap avoids disadvantages such as insensate coverage, a two-stage procedure associated with the cross-foot flap, a paucity of expandable local tissue associated with local skin flaps, sacrifice of main arteries and nerves (medial and 
lateral plantar arteries and nerves), venous congestion and need for an extended dissection associated with the sural flap and the need for skilled personal and sophisticated equipment associated with microsurgical flaps. ${ }^{9,11}$ Lateral calcaneal artery flaps are limited in size but can fill defects of the posterior heel satisfactorily. In the present study, all flaps survived well. There was minimal epidermal necrosis in $1(10 \%)$ case and only partial skin graft loss occurred in $2(20 \%)$ cases which healed conservatively without need of surgery. All flaps inset areas were aesthetically good except the donor areas which showed a little depression. There was no sensation loss in flap area but sensory disturbance at the lateral part of the dorsum of foot was found in all cases. ${ }^{9}$ This study has confirmed the usefulness of lateral calcaneal artery flap in the coverage of intractable posterior heel defects with or without bone or tendon exposure with minimal donor site morbidity.

\section{Conclusion}

The goal of reconstruction is to provide sensate and stable coverage for posterior heel soft tissue defect with minimal donor site morbidity. The lateral calcaneal artery skin flap fulfills all these requirements and therefore this flap can be used to cover difficult wounds of the posterior heel of the foot.

\section{References}

1. Bajantri B, Bharathi RR, Sabapathy SR. Wound coverage considerations for defects of the lower third of the leg. Indian J Plast Surg 2012;45(2):283-90.
2. Suri MP, Patel AG, Vora HJ, Raibagkar SC, Mehta DR, Vyas UH. Post-traumatic posterior heel soft tissue defect reconstruction. Indian $\mathrm{J}$ Plast Surg 2005;38(2):138-43.

3. Grabb WC, Argenta LC. The lateral calcaneal artery skin flap (the lateral calcaneal artery, lesser saphenous vein, and sural nerve skin flap). Plast Reconstr Surg 1981;68(5):723-30.

4. Holmes J, Rayner CR. Lateral calcaneal artery island flaps. $\mathrm{Br} \mathrm{J}$ Plast Surg 1984;37(3):402-5.

5. Ishikawa K, Isshiki N, Hoshino K, Mori C. Distally based lateral calcaneal flap. Ann Plast Surg 1990;24(1):10-6.

6. Ishikawa K, Kyutoku S, Takeuchi E. Free lateral calcaneal flap. Ann Plast Surg 1993;30(2):167-70.

7. Cheema TA, Saleh ES, De Carvalho AF. The distally based sural artery flap for ankle and foot coverage. J Foot Ankle Surg 2007;46(1):40-7.

8. Demirtas $Y$, Ayhan S, Sariguney $Y$, et al. Distally based lateral and medial leg adipofascial flaps: need for caution with old, diabetic patients. Plast Reconstr Surg 2006;117(1):272-6.

9. Hovius SE, Hofman A, van der Meulen JC. Experiences with the lateral calcaneal artery flap. Ann Plast Surg 1988;21(6):532-5.

10. Lin SD, Lai CS, Chiu YT, Lin TM. The lateral calcaneal artery adipofascial flap. Br J Plast Surg 1996;49(1):52-7.

11. Chang $\mathrm{H}$, Kwon SS, Minn KW. Lateral calcaneal artery as a recipient pedicle for microsurgical foot reconstruction. J Plast Reconstr Aesthet Surg 2010;63(11):1860-4.

\section{Suggestion for citation of the above:}

Islam MT, SN Abdullah, MJ Uddin, TR Rahman. Use of lateral calcaneal flap for coverage of posterior heel defects. Mediscope 2017;4(1):5-10. 